\title{
Desenvolvimento e caracterização de filmes de base celulósica incorporados com aldeído cinâmico
}

\author{
Development and characterization of cellulose-based \\ films with cinnamaldehyde incorporated
}

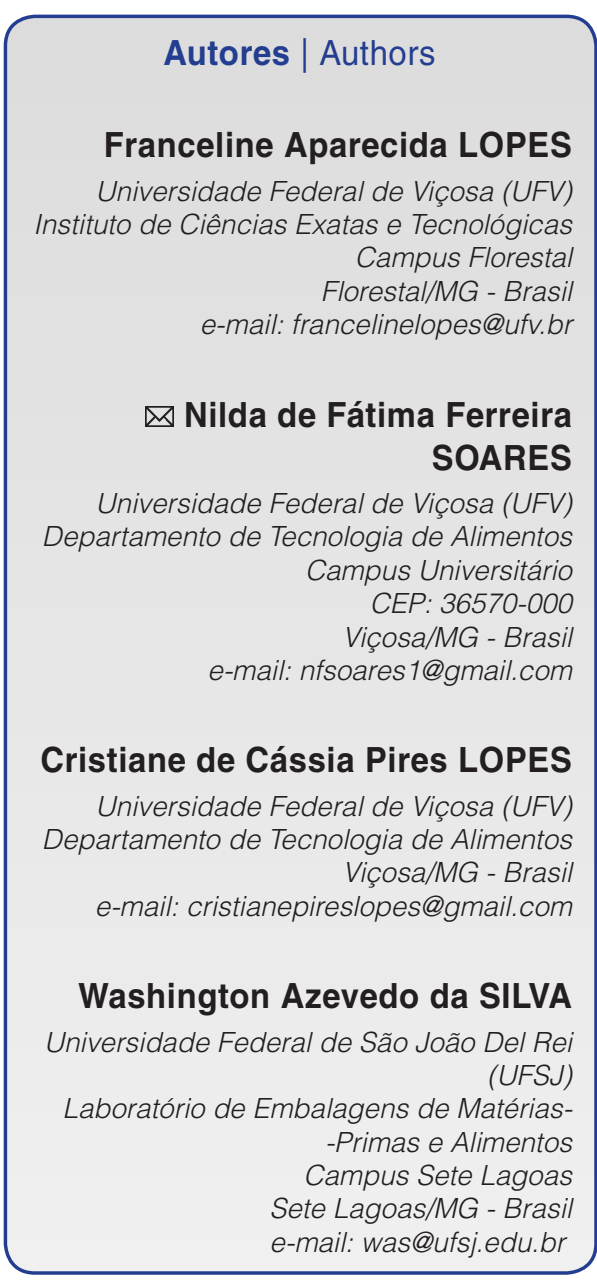

Autor Correspondente / Corresponding Author

Recebido / Received: 13/08/2013 Aprovado / Approved: 13/03/2014 Publicado / Published: mar./2014

\section{Resumo}

Filmes antimicrobianos foram desenvolvidos com a incorporação de aldeído cinâmico nas concentrações de 5\%, 10\% e 20\% v/p. Suas atividades de inibição do crescimento foram avaliadas para as bactérias Staphylococcus aureus, Listeria monocytogenes e Escherichia coli e para os fungos Fusarium oxysporum e Aspergillus flavus. As propriedades mecânicas dos filmes também foram avaliadas. Para as bactérias, à exceção de E. coli, foram observados halos de inibição que aumentaram proporcionalmente ao aumento da concentração de aldeído cinâmico no filme. A espessura média dos filmes utilizados, independentemente da concentração, foi de 32,47 $\mu \mathrm{m}$ e a média de deformação relativa na carga máxima dos filmes foi de $2,05 \%$ a $8{ }^{\circ} \mathrm{C}$ e $1,73 \%$ a $25^{\circ} \mathrm{C}$. O filme contendo $10 \%$ de aldeído cinâmico apresentou carga máxima de deformação de $108,27 \mathrm{~N}$ (Newton), significativamente menor $(p<0,05)$ que os filmes com $0 \%$ e $5 \%$. Os resultados mostraram que o uso de filmes incorporados com aldeído cinâmico é uma alternativa como embalagem ativa para o controle do crescimento de micro-organismos em produtos alimentícios.

Palavras-chave: Embalagem ativa; Filmes antimicrobianos; Teste do halo; Permeabilidade ao vapor d'água; Propriedades mecânicas.

\section{Summary}

Antimicrobial films were developed with the incorporation of cinnamaldehyde at 5, 10 and $20 \% \mathrm{v} / \mathrm{w}$. The growth inhibition activities of the films were evaluated for the bacteria Staphylococcus aureus, Listeria monocytogenes and Escherichia coli and for the fungi Fusarium oxysporum and Aspergillus flavus. Their mechanical properties were also evaluated. For the bacteria, with the exception of $E$. coli, the inhibition zones increased with the increase in concentration of cinnamaldehyde in the film. Regardless of the cinnamaldehyde concentration the average film thickness was $32.47 \mu \mathrm{m}$ and the mean relative deformation at maximum film load was $2.05 \%$ at $8{ }^{\circ} \mathrm{C}$ and $1.72 \%$ at $25^{\circ} \mathrm{C}$. The film containing $10 \%$ of cinnamaldehyde showed a maximum load of $108.26 \mathrm{~N}$, significantly lower $(p<0.05)$ than the films with $0 \%$ and $5 \%$. The results showed the potential of the films with cinnamaldehyde incorporated as alternative active packaging for the control of the growth of microorganisms in foods.

Key words: Active packaging; Antimicrobial films; Halo test; Steam permeability; Mechanical properties. 


\section{Introdução}

Atualmente, as indústrias alimentícias trabalham para buscar tecnologias que atentam às novas exigências do mercado que incluem segurança microbiológica e qualidades sensoriais e nutricionais dos produtos alimentícios. As embalagens, por sua vez, possuem papel fundamental para manutenção da qualidade na cadeia produtiva, de forma a oferecer proteção contra fatores internos (ação de micro-organismos) e externos (luz e oxigênio) de deterioração.

Com o intuito de aumentar a proteção oferecida pelas embalagens, uma nova linha de pesquisa tem crescido consideravelmente levando em consideração a interação direta da embalagem com o produto alimentício, diminuindo características não desejadas. Essas embalagens são denominadas ativas e entre vários exemplos podem ser citados os filmes antimicrobianos, os filmes antioxidantes, filmes contendo enzimas ou aromas e os sachês absorvedores de etileno, de oxigênio e de umidade (OLIVEIRA et al., 2010; YAMASHITA et al., 2006; OZDEMIR e FLOROS, 2004). Os filmes antimicrobianos possibilitam a redução ou remoção dos aditivos aos alimentos e a incorporação diretamente na matriz polimérica da embalagem.

Vários compostos têm sido propostos e testados para a atividade antimicrobiana em embalagens de alimentos, incluindo sais de ácidos orgânicos tais como o sorbato e propionato, benzoato (HAN e FLOROS, 1997), bacteriocinas como a nisina e pediocina (MING et al., 1997); óleo essencial de manjericão (SUPPAKUL et al., 2003, 2011); quitosana; triclosan; extratos vegetais; enzimas tais como a lisozima e lactoperoxidase (JOERGER, 2007) e outros.

O aldeído cinâmico, um composto extraído da casca de canela, é utilizado principalmente para dar sabor e aroma de canela a alimentos e bebidas e aroma a produtos médicos, cosméticos e perfumes. Sua atividade antimicrobiana também foi estudada e os resultados indicam que ele tem um elevado potencial de aplicação para essa finalidade (ROLLER e SEEDHAR, 2002; KWON et al., 2003; KIM et al., 2004; GILL e HOLLEY, 2004; MATAN et al., 2006; CHENG et al., 2006). Estudos também demonstraram o uso potencial de aldeído cinâmico em filmes ou revestimento de embalagem antimicrobiana como o realiazado por Sanla-Ead et al. (2012). Neste trabalho de pesquisa, foi avaliada a atividade antimicrobiana do aldeído cinâmico incorporado em filmes de metilcelulose contra dez bactérias patogênicas e de deterioração e três cepas de leveduras, os resultados mostraram que os filmes produzidos apresentavam atividade antimicrobiana contra todas as cepas-teste.

Portanto, neste trabalho, objetivou-se desenvolver, testar a atividade antimicrobiana in vitro e caracterizar filmes de base celulósica (acetato de celulose) incorporados com aldeído cinâmico.

\section{Material e métodos}

\subsection{Preparo dos filmes}

Os filmes foram elaborados com acetato de celulose (Rhodia, Freiburg, Alemanha) e acetona P.A. (Vetec $\AA$, RJ, Brasil) e processados utilizando o método casting, descrito por Soares e Hotchkiss (1998) com algumas modificações. De acordo com esta metodologia, o acetato de celulose foi dissolvido em acetona, porém sem a adição de plastificante. Depois da solubilização, o aldeído cinâmico (Sigma-Aldrich, São Paulo-SP) foi incorporado na emulsão celulósica nas concentrações de 5\%, 10\% e $20 \%$ v/p em relação ao peso da matriz polimérica, obtendo-se assim três filmes diferentes. Paralelamente, filme-controle sem adição de antimicrobiano (0\%) foi preparado.

Depois da completa evaporação do solvente em dessecador a vácuo, os filmes foram separados por folhas de papel branco e armazenados à temperatura ambiente para análises posteriores.

\subsection{Atividade antimicrobiana dos filmes - Teste do halo}

Com a finalidade de testar a atividade antimicrobiana dos filmes, foram utilizadas duas bactérias Grampositivas, Staphylococcus aureus (ATCC 6538) e Listeria monocytogenes (ATCC 153113), uma bactéria Gram-negativa, Escherichia coli (ATCC 11229), e dois fungos filamentosos, Fusarium oxysporum e Aspergillus flavus, escolhidos de acordo com a disponibilidade no laboratório.

Os meios de cultura utilizados para o experimento, utilizando Staphylococcus aureus, Listeria monocytogenes, Escherichia coli, foram Agar Baird Parker, Oxford e Violet Red Bile Agar (VRB), respectivamente, e Potato Dextrose Agar (BDA) para os fungos filamentosos.

Placas de Petri foram preparadas em duplicata e, após solidificação do meio, foi inoculado $0,1 \mathrm{~mL}$ das respectivas culturas previamente ativadas e padronizadas para número de células aproximado de $1 \times 10^{4} \mathrm{UFC} \cdot \mathrm{mL}^{-1}$ (MELO, 2003).

Os filmes foram cortados em círculos de $1 \mathrm{~cm}$ de diâmetro e esterilizados em câmara com lâmpada de UV (Prodicil, 110 V, $254 \mathrm{~nm}$ ) por 10 minutos. Em seguida, três pedaços de filme, um controle e dois com a mesma concentração, foram colocados assepticamente nas placas de Petri previamente inoculada com bactéria ou fungo-teste. As placas inoculadas com as bactérias foram incubadas a $37^{\circ} \mathrm{C}$ por 48 horas e as placas inoculadas 
com os fungos, a $25^{\circ} \mathrm{C}$ por $72-120$ horas. Todas as placas foram elaboradas em duplicatas.

O teste também foi realizado a $8{ }^{\circ} \mathrm{C}$ para todos os micro-organismos até a formação de colônias com o intuito de simular resultados referentes à temperatura de refrigeração de produtos alimentícios.

Depois do período de incubação, o diâmetro dos halos formados ao redor do filme foi medido com o auxílio de uma régua.

\subsection{Caracterização dos filmes}

Os testes posteriores foram realizados apenas com os filmes nas concentrações de 0,5\% e 10\%, uma vez que, apesar dos resultados satisfatórios alcançados com o filme na concentração de $20 \%$ de aldeído cinâmico, testes preliminares constataram que, nessa concentração, os filmes provocaram sabor e odor muito acentuados de canela em pães e massas de pastel embalados com esse filme, afetando suas características sensoriais.

\subsubsection{Determinação da espessura}

Para determinação da espessura dos filmes, foram utilizadas dez amostras de cada filme e a medida foi realizada com o auxílio de um micrômetro Mitutoyo (0-25 mm). A avaliação foi conduzida em delineamento inteiramente casualizado, com três tratamentos e 10 repetições, e os resultados foram submetidos à análise de variância e ao teste de Tukey a 5\% de probabilidade pelo emprego do programa SAS (Statistical Analysis System - SAS Institute Inc., North Carolina, USA), versão 9.1, licenciado para a Universidade Federal de Viçosa.

\subsubsection{Análise das propriedades mecânicas}

As propriedades mecânicas dos filmes foram medidas por meio do determinador universal de teste (INSTRON série 3367) com carga de $1 \mathrm{kN}$ e velocidade de $50,8 \mathrm{~cm} \cdot \mathrm{min}^{-1}$.

Para tanto, 15 amostras de cada filme foram cortadas em retângulos de $2,5 \mathrm{~cm}$ de largura por $15 \mathrm{~cm}$ de comprimento e acondicionadas a $23 \pm 2{ }^{\circ} \mathrm{C} / 50 \pm 5 \%$ UR por 24 horas. Nesse teste, foram determinadas a carga máxima e a deformação relativa na carga máxima a $8{ }^{\circ} \mathrm{C}$ e a $25^{\circ} \mathrm{C}$ em câmara climatizada a $75 \% \pm 5 \%$ de umidade relativa (UR).

As avaliações dessas características foram conduzidas em delineamento inteiramente casualizado, em um esquema fatorial ( $3 \times 2)$, três concentrações e duas temperaturas, com 15 repetições e os resultados submetidos à análise de variância e ao teste de Tukey, utilizando-se o programa estatístico SAS.

\subsubsection{Determinação da permeabilidade ao vapor d’água}

A permeabilidade dos filmes ao vapor d'água foi determinada segundo Oliveira et al. (1996). Foram utilizadas 3 amostras de cada filme com $50 \mathrm{~cm}^{2}$ e o experimento, realizado em dessecadores com solução saturada de $\mathrm{NaCl}\left(75 \%\right.$ UR) a $25^{\circ} \mathrm{C}$. As pesagens foram realizadas durante 15 dias em triplicata. No primeiro dia, foram realizadas pesagens de 2 em 2 horas, durante 6 horas e, nos dias seguintes, pesagens com intervalos de 24 horas. A permeabilidade foi determinada pela declividade da curva resultante da plotagem peso $\mathrm{x}$ tempo e expressa em g. $\mathrm{m}^{-2} \cdot \mathrm{dia}^{-1}$.

A avaliação foi conduzida em delineamento inteiramente casualizado e os resultados obtidos para os diferentes tratamentos, submetidos à análise de variância e ao teste de Tukey, utilizando-se o programa estatístico SAS.

\section{Resultados e discussão}

\subsection{Filmes antimicrobianos}

\subsubsection{Atividade antimicrobiana}

No filme antimicrobiano incorporado com $5 \%$ de aldeído cinâmico, observou-se a formação de um halo de $1,5 \mathrm{~cm}$ para $A$. flavus, enquanto que, para as concentrações de $10 \%$ e $20 \%$, não foi observado crescimento desse micro-organismo (Figura 1a). Jham et al. (2005) também verificaram o efeito antimicrobiano do aldeído cinâmico no crescimento de $A$. flavus. Neste experimento, ao fracionarem extrato de óleo de casca de canela, observaram que uma das frações continha $99,1 \%$ de aldeído cinâmico e, ao testarem a sua eficiência na inibição do crescimento de A. flavus, verificaram $100 \%$ de redução do crescimento do micro-organismo, a qual foi relacionada à elevada porcentagem de aldeído cinâmico na fração testada.

No teste com o F. oxysporum, observou-se inibição completa do crescimento em torno dos filmes ativos nas três concentrações testadas após 120 horas (Figura 1b). Nas placas que continham filmes com $20 \%$ de aldeído cinâmico, constatou-se a inibição do micro-organismo, inclusive ao redor do filme-controle. Neste caso, pode ter ocorrido uma difusão do aldeído cinâmico a partir dos filmes com $20 \%$ em uma concentração suficiente para inibir o crescimento dos fungos filamentosos em toda a placa.

O aldeído cinâmico é descrito em diversos trabalhos como um excelente agente antifúngico. Sivakumar et al. (2002) verificaram inibição completa do crescimento dos fungos filamentosos Botryodiplodia theobromae, Colletotrichum gloeosporioides e Gliocephalotrichum 

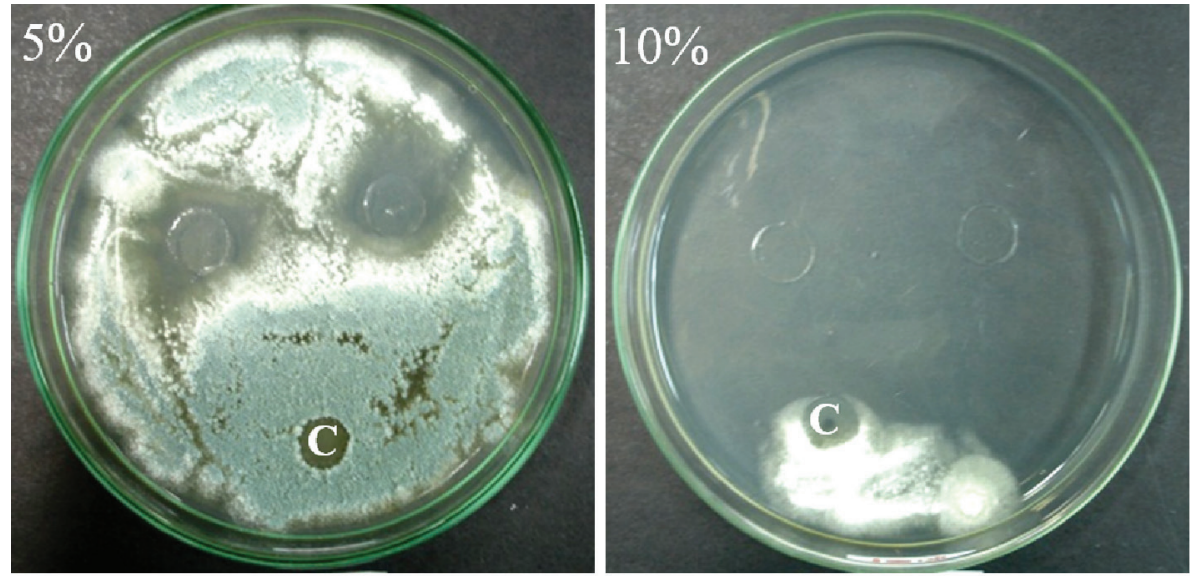

(a) Aspergillus flavus
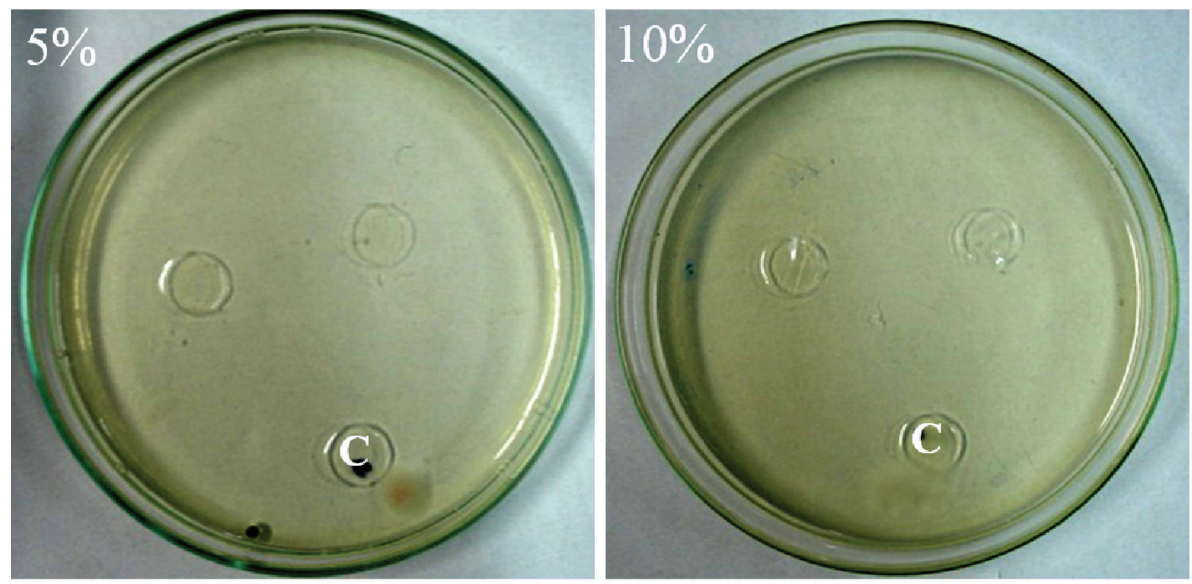

(b) Fusarium oxysporum
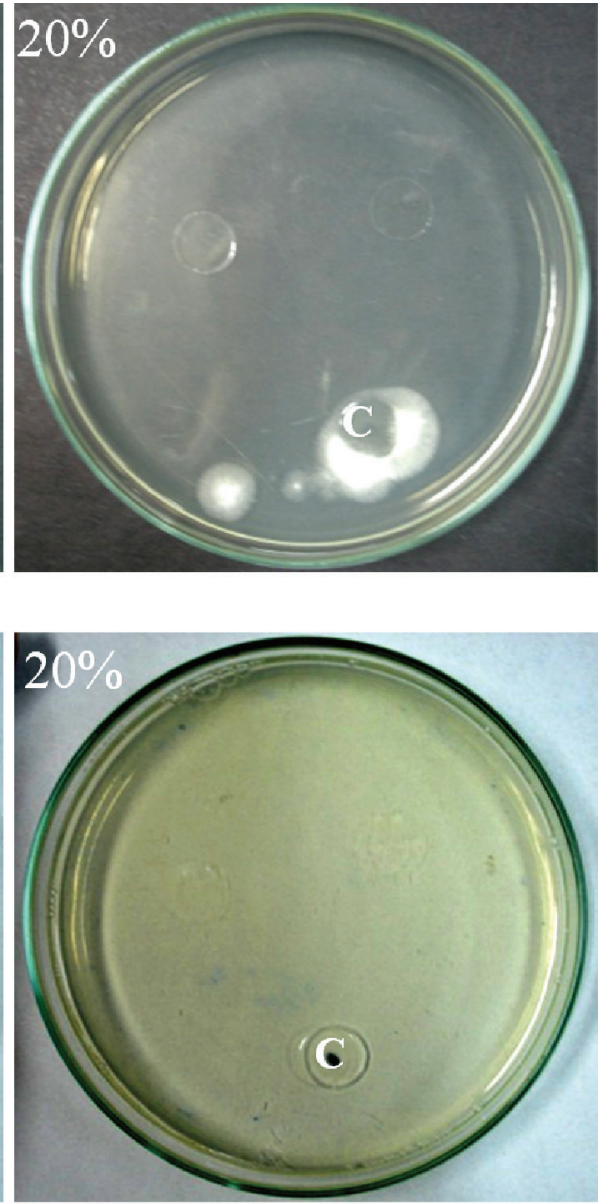

Figura 1. Figura representativa do halo de inibição do crescimento de Aspergillus flavus e de Fusarium oxysporum em torno dos filmes incorporados com diferentes concentrações de aldeído cinâmico, após 120 horas de incubação a $25^{\circ} \mathrm{C}$. Cada placa continha um filme controle, sem o aldeído cinâmico, representado pela letra C.

microchlamydosporum com a aplicação de uma solução aquosa de aldeído cinâmico de concentração de 30 ppm a $28{ }^{\circ} \mathrm{C}$. Cheng et al. (2006) também constataram a presença de atividade antifúngica do óleo essencial de folhas de canela contra Lenzites betulina, Trametes versicolor e Laetiporus sulphureus. Nesse trabalho, os autores atribuíram a atividade antifúngica do óleo à presença de aldeído cinâmico.

Nas placas inoculadas com $S$. aureus, foi observada inibição de crescimento em todas as concentrações avaliadas com formação de halos de 3,5, 5 e 4,5 cm para as concentrações de 5\%, 10\% e 20\%, respectivamente (Figura 2a). Kwon et al. (2003) testaram o efeito antimicrobiano do aldeído cinâmico contra a bactéria patogênica S. aureus e verificaram $70 \%$ de redução do crescimento na presença de $0,4 \mathrm{ml} \cdot \mathrm{L}^{-1}$ de aldeído cinâmico adicionado diretamente na suspensão de célula em caldo BHI.
O crescimento de Listeria monocytogenes foi inibido ao redor dos filmes antimicrobianos e houve apenas diferenciação no crescimento de células entre as diferentes concentrações, ou seja, maior crescimento nas placas com o filme a $5 \%$ e menor naquela com filme a 20\% (Figura 2b). Em torno do filme-controle, foi observado crescimento do micro-organismo em todas as placas. Yamazaki et al. (2004) também constataram inibição do crescimento de Listeria monocytogenes com a aplicação do aldeído cinâmico diretamente na suspensão de células.

Para Escherichia coli, não houve formação do halo de inibição do crescimento nos filmes testados. Entretanto, houve diferenciação de concentração do crescimento (Figura 2c), ou seja, pode-se constatar que, no local de contato do filme com o ágar, não houve crescimento de colônias.

Toledo (2000) afirmou que a formação de halo de inibição está relacionada com a difusão do antimicrobiano 

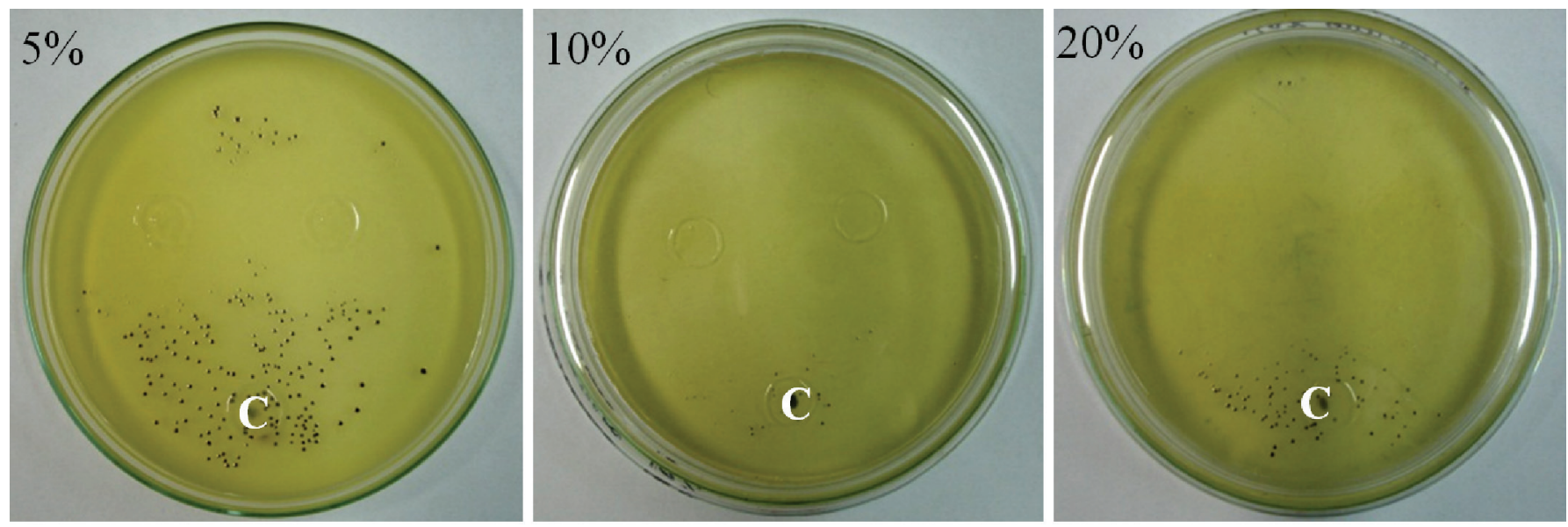

(a) Staphylococcus aureus
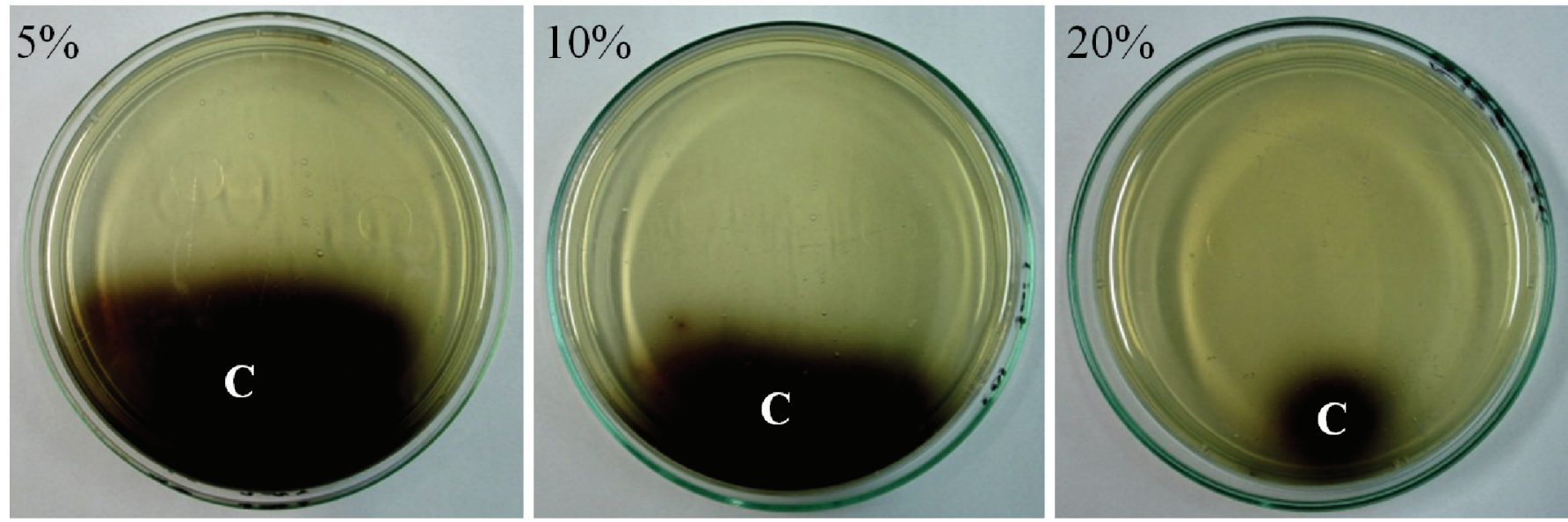

(b) Listeria monocytogenes
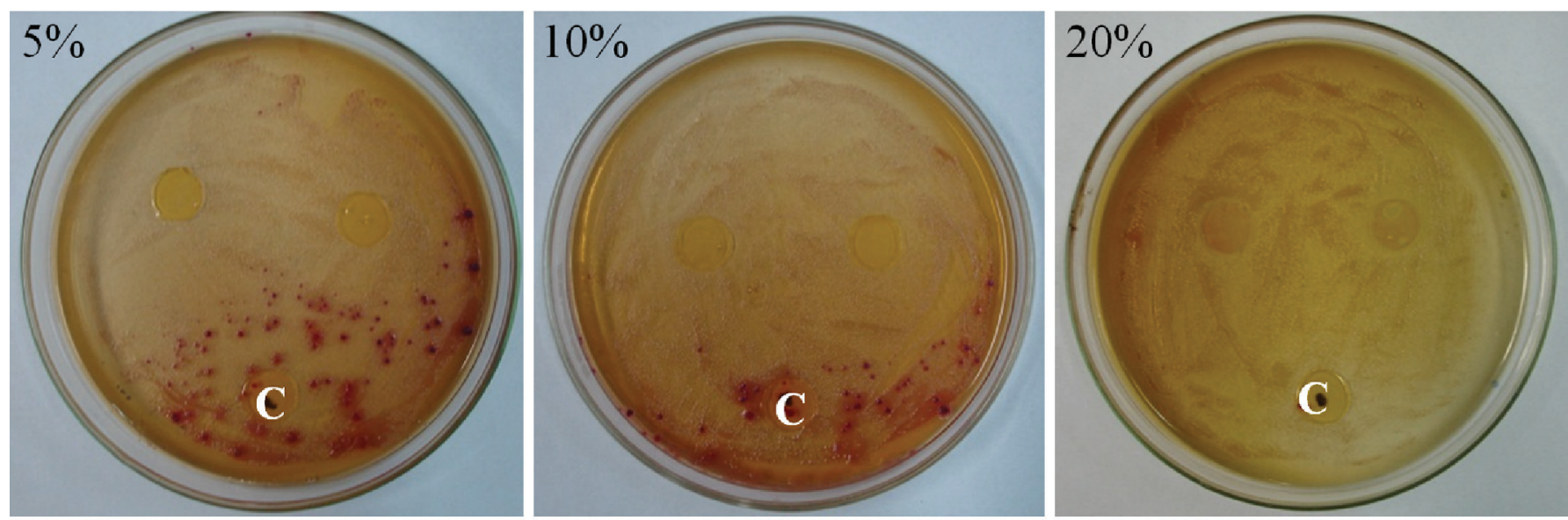

(c) Escherichia coli

Figura 2. Crescimento de Staphylococcus aureus, Listeria monocytogenes e Escherichia coli em torno dos filmes incorporados com diferentes concentrações de aldeído cinâmico, após 48 horas de incubação a $37^{\circ} \mathrm{C}$. Cada placa continha um filme controle, sem o aldeído cinâmico, representado pela letra C.

e com a velocidade de crescimento do micro-organismo e que estes fatores sofrem influência do estado fisiológico da cultura indicadora e da composição do ágar. Além disso, Melo (2003) avaliou a eficiência do filme incorporado com nisina pelo teste do halo em meios de cultura como
Plate Count Agar (PCA), Agar Brain Heart Infusion (BHI) e Agar Baird-Parker inoculados com Staphylococcus sp. Concluiu-se que os micro-organismos inoculados em Baird-Parker apresentaram a maior formação de halo, seguidos dos meios PCA e BHI. O autor atribuiu essa 
diferença à composição dos meios, uma vez que os meios PCA e BHI possuem maior disponibilidade de nutrientes, o que permite maior velocidade de crescimento do microorganismo comparado à velocidade de difusão da nisina para o meio de cultura.

Com base nessas observações, pode-se concluir que não ocorreu difusão do aldeído cinâmico em quantidades suficientes para inibição do crescimento da E. coli no ágar utilizado, uma vez que não houve crescimento no local de contato do filme.

Comparando as duas temperaturas de inibição testadas, observou-se que não houve diferença entre os halos de inibição obtidos com a temperatura de refrigeração e a temperatura ótima de crescimento do micro-organismo. No entanto, à temperatura de refrigeração o crescimento foi mais lento. Assim, a visualização de células de $S$. aureus ocorreu após dois dias de incubação para a temperatura de $37^{\circ} \mathrm{C}$ e após dez dias para a temperatura de $8^{\circ} \mathrm{C}$.

$\mathrm{Na}$ avaliação da atividade antimicrobiana dos filmes, observou-se maior eficiência sobre os fungos filamentosos. Entre as bactérias, constatou-se maior eficiência antimicrobiana do aldeído cinâmico sobre bactérias Gram-positivas. Segundo Delaquis et al. (2002), as razões para a maior resistência das bactérias Gram-negativas a compostos antimicrobianos naturais hidrofóbicos não estão ainda totalmente esclarecidas, no entanto, essa diferença pode estar relacionada a diferenças da membrana celular desses dois grupos de bactérias. As bactérias Gram-negativas possuem uma membrana externa constituída de lipopolissacarídeos que apresentam baixa permeabilidade e não permitem a difusão de compostos hidrofóbicos (NIKAIDO, 1989).

\subsubsection{Caracterização dos filmes}

Os resultados posteriores são apresentados para os filmes nas concentrações de 0, 5\% e 10\%. Destaca-se que as amostras com $20 \%$ de aldeído cinâmico foram excluídas como justificado no item 2.3.

Pode-se observar que a concentração de aldeído cinâmico não afetou significativamente $(p \geq 0,05)$ a espessura dos filmes, os valores obtidos apresentaram média de 32,47 $\mu \mathrm{m}$, e não afetaram também, independentemente da temperatura, a sua deformação relativa (Tabela 1). No entanto, a carga máxima de deformação (N) foi afetada em ambas as temperaturas testadas, tendo sido observado que o filme adicionado de $10 \%$ de aldeído cinâmico apresentou carga máxima de deformação significativamente $(p<0,05)$ menor $(108,27$ $\mathrm{N})$ que a dos filmes $0 \%(122,07 \mathrm{~N})$ e $5 \%(120,58 \mathrm{~N})$, os quais não apresentaram diferença significativa $(p \geq 0,05)$ entre si (Tabela 1). A diminuição da carga máxima de deformação com o aumento da concentração do aditivo pode estar relacionada a alterações na plasticidade do filme produzido, ou seja, o aldeído cinâmico pode estar exercendo a função de um plastificante, alterando as propriedades mecânicas do filme. A diminuição da carga máxima de deformação com o aumento da concentração do aditivo incorporado, apesar da porcentagem de deformação constante, também foi verificada por Limjaroen et al. (2003) e Silveira (2005), e, segundo Appendini e Hotchkiss (2002), as propriedades do polímero são influenciadas para cada combinação antimicrobiano-polímero.

A temperatura de determinação das propriedades mecânicas do filme, por sua vez, influenciou significativamente $(p<0,05)$ os valores de deformação e os valores de carga máxima verificados para os três filmes. Os filmes a $8^{\circ} \mathrm{C}$ apresentaram maior deformação (\%) e carga máxima (N) quando comparados aos filmes avaliados a $25^{\circ} \mathrm{C}$ (Tabela 2). Em geral, a elevação da temperatura aumenta a flexibilidade dos filmes flexíveis em função de maior movimentação das cadeias, o que diminui a força necessária para o seu rompimento (ROBERTSON, 2005).

Os resultados observados de permeabilidade ao vapor d'água estão representados na Tabela 3. Observou-se diminuição da permeabilidade ao vapor d'água com o aumento da concentração do aldeído cinâmico. A difusão das moléculas de água através do filme é dificultada pela presença do aldeído cinâmico e pela sua hidrofobicidade. Diferença significativa $(p \leq 0,05)$ foi observada entre as amostras-controle (0\%) e $10 \%$.

Tabela 1. Deformação relativa na carga máxima e carga máxima de deformação de filmes com diferentes concentrações de aldeído cinâmico.

\begin{tabular}{ccccc} 
Temperatura & \multicolumn{2}{c}{ Deformação relativa na carga máxima (\%) } & \multicolumn{2}{c}{ Carga máxima de deformação (N) } \\
\cline { 2 - 5 } Filme & $\mathbf{8}^{\circ} \mathbf{C}$ & $\mathbf{2 5}^{\circ} \mathbf{C}$ & $\mathbf{8}^{\circ} \mathbf{C}$ & $118,97 \mathrm{a}$ \\
$0 \%$ & $2,02 \mathrm{a}$ & $1,65 \mathrm{a}$ & $125,18 \mathrm{a}$ & $117,19 \mathrm{a}$ \\
$5 \%$ & $2,21 \mathrm{a}$ & $1,77 \mathrm{a}$ & $123,96 \mathrm{a}$ & $106,93 \mathrm{~b}$ \\
$10 \%$ & $1,93 \mathrm{a}$ & $1,76 \mathrm{a}$ & $109,60 \mathrm{~b}$ & \\
\hline
\end{tabular}

Médias seguidas de mesma letra, nas colunas, não diferem entre si a 5\% de probabilidade, pelo teste de Tukey. 
Desenvolvimento e caracterização de filmes de base celulósica incorporados com aldeído cinâmico LOPES, F. A. et al.

Tabela 2. Média dos valores de carga máxima e deformação relativa na carga máxima dos filmes nas duas temperaturas testadas.

\begin{tabular}{ccc} 
Temperatura & $\begin{array}{c}\text { Carga máxima } \\
\text { média (N) }\end{array}$ & $\begin{array}{c}\text { Deformação } \\
\text { média (\%) }\end{array}$ \\
\hline $8^{\circ} \mathrm{C}$ & $119,58 \mathrm{a}$ & 2,05 \\
$25^{\circ} \mathrm{C}$ & $114,37 \mathrm{~b}$ & 1,73 \\
\hline
\end{tabular}

Médias seguidas de mesma letra, nas colunas, não diferem entre si a $5 \%$ de probabilidade, pelo teste de Tukey.

Tabela 3. Permeabilidade ao vapor d'água dos filmes adicionados de 0\%,5\% e 10\% de aldeído cinâmico.

\begin{tabular}{ccc} 
Filme & $\begin{array}{c}\text { Taxa de permeabilidade } \\
\left(\mathbf{g} \cdot \mathbf{m}^{-2} \cdot \mathbf{d i a}^{-\mathbf{1}} \mathbf{)}\right.\end{array}$ & $\sigma$ \\
\hline $0 \%$ & $10,48 \mathrm{a}$ & 0,89 \\
$5 \%$ & $8,92 \mathrm{ab}$ & 0,78 \\
$10 \%$ & $8,28 \mathrm{~b}$ & 0,50 \\
\hline
\end{tabular}

Espessura média dos filmes: $32,47 \mu \mathrm{m}$; e umidade relativa: $75 \%$. Médias seguidas de mesma letra, nas colunas, não diferem entre si a $5 \%$ de probabilidade, pelo teste de Tukey.

\section{Conclusões}

Os filmes apresentaram ação antimicrobiana principalmente sobre os fungos Aspergillus flavus e Fusarium oxysporume sobre as bactérias Gram-positivas Staphylococcus aureus e Listeria monocytogenes, corroborando com outros autores que usaram o aldeído cinâmico em vários micro-organismos.

Os filmes incorporados com 0\%, 5\% e 10\% de aldeído cinâmico não diferiram significativamente ( $p$ $\geq 0,05$ ) quanto à espessura e deformação relativa na carga máxima. No entanto, o filme incorporado de 10\% de aldeído cinâmico apresentou carga máxima de deformação significativamente menor $(p<0,05)$ que os outros tratamentos testados nesse experimento, assim como menor permeabilidade ao vapor d'água, provavelmente pela maior concentração de aldeído, seu efeito plastificante e sua hidrofobicidade.

Observou-se também nesse experimento que a temperatura de armazenamento influenciou significativamente $(p<0,05)$ as propriedades mecânicas do filme.

Por meio dos resultados, verificou-se que o uso de filmes incorporados com aldeído cinâmico é uma alternativa como embalagem ativa para o controle do crescimento de micro-organismos deterioradores e patogênicos em produtos alimentícios.

\section{Referências}

APPENDINI, P.; HOTCHKISS, J. H. Review of antimicrobial food packaging. Innovative Food Science and Emerging Technologies, Amsterdam, v. 3, n. 2, p. 113-126, 2002. http:// dx.doi.org/10.1016/S1466-8564(02)00012-7
CHENG, S. S.; LIU, J. Y.; HSUI, Y. R.; CHANG, S. T. Chemical polymorphism and antifungal activity of essential oils from leaves of different provenances of indigenous cinnamon (Cinnamomumosmophloeum). Bioresource Technology, Barking, v. 97, n. 2, p. 306-312, 2006.

DELAQUIS, P. J.; STANICH, K.; GIRARD, B.; MAZZA, G. Antimicrobial activity of individual and mixed fractions of dill, cilantro, coriander and eucalyptus essential oils. International Journal of Food Microbiology, Amsterdam, v. 74, n. 1-2, p. 101-109, 2002. http://dx.doi.org/10.1016/S01681605(01)00734-6

GILL, A. O.; HOLLEY, R. A. Mechanisms of bactericidal action of cinnamaldehyde against Listeria monocytogenes and of Eugenol against $L$. monocytogenes and Lactobacillus sakei. Applied and Environmental Microbiology, Washington, v. 70, n. 10, p. 5750-5755, 2004. PMid:15466510 PMCid:PMC522076. http://dx.doi.org/10.1128/AEM.70.10.5750-5755.2004

HAN, J. H.; FLOROS, J. D. Casting antimicrobial packaging films and measuring their physical properties and antimicrobial activity. Journal of Plastic Film and Sheeting, Rochester, v. 13, n. 4, p. 287-2598, 1997.

JHAM, G. N.; DHINGRA, O. D.; JARDIM, C. M.; VALENTE, V. M. M. Identification of the major fungitoxic component ofcinnamon bark oil. Fitopatologia Brasileira, Brasília, v. 30, n. 4, p. 404-408, 2005.

JOERGER, R. D. Antimicrobial films for food applications: a quantitative analysis of their effectiveness. Packaging Technology and Science, Singapore, v. 20, n. 4, p. 231-273, 2007. http://dx.doi.org/10.1002/pts. 774

KIM, H. O.; PARK, S. W.; PARK, H. D. Inactivation of Escherichia coli O157:H7 by cinnamic aldehyde purified from Cinnamomum cassia shoot. Food Microbiology, London, v. 21, n. 1, p. 105-110, 2004. http://dx.doi.org/10.1016/S0740-0020(03)00010-8

KWON, J. A.; YU, C. B.; PARK, H. D. Bactericidal effects and inhibition of cell separation of cinnamic aldehyde on Bacillus cereus. Letters in Applied Microbiology, Oxford, v. 37, n. 1, p. 61-65, 2003. http://dx.doi.org/10.1046/j.1472765X.2003.01350.X

LIMJAROEN, P.; RYSER, E.; LOCKHART, H.; HARTE, B. Development of a food packaging coating material with antimicrobial properties. Journal of Plastic Film and Sheeting, New York, v. 19, n. 2, p. 95-109, 2003. http://dx.doi. org/10.1177/8756087903039409

MATAN, N.; RIMKEEREE, H.; MAWSON, A. J.; CHOMPREEDA, P.; HARUTHAITHANASAN, V.; PARKER, M. Antimicrobial activity of cinnamon and clove oils under modified atmosphere conditions. International Journal of Food Microbiology, Amsterdam, v. 107, n. 2, p. 180-185, 2006. PMid:16266767. http://dx.doi. org/10.1016/j.ijfoodmicro.2005.07.007 
Desenvolvimento e caracterização de filmes de base celulósica incorporados com aldeído cinâmico LOPES, F. A. et al.

MELO, N. R. Avaliação de Embalagem Ativa por Incorporação de Nisina na Inibição de Staphylococcus sp. 2003. 70 f. Dissertação (Mestrado em Ciência e Tecnologia de Alimentos)Universidade Federal de Viçosa, Viçosa, 2003.

MING, X.; WEBER, G. H.; AYRES, J. W.; SANDINE, W. E. Bacteriocins applied to food packaging materials to inhibit Listeria monocytogenes on meats. Journal of Food Science, Chicago, v. 62, n. 2, p. 413-415, 1997. http://dx.doi. org/10.1111/j.1365-2621.1997.tb04015.x

NIKAIDO, H. Outer membrane barrier as a mechanism of antimicrobial resistance: minireview. Antimicrobial Agentes and Chemotherapy, Washington, v. 33, n. 11, p. 1831-1836, 1989. http://dx.doi.org/10.1128/AAC.33.11.1831

OLIVEIRA, L. M.; ALVES, R. M. V.; SARANTÓPOULOS, C. I. G. L.; PADULA, M.; GARCIA, L. Ensaios para Avaliação de Embalagens Plásticas Flexíveis. Campinas: CETEA/ITAL, 1996. 219 p.

OLIVEIRA, A. N.; MARTINS, M. C. P.; OLIVEIRA, C. G.; LOPES, M. L. S.; MATTOS, J. C. S.; ESPITIA, P. J. P.; PEREIRA, J. M. A. T. K.; MELO, N. R.; SOARES, N. F. F. Avaliação de filme ativo aromatizante e sua aplicação em presunto cozido. Brazilian Journal of Food Technology, Campinas, v. 13, n. 4, p. 299-305, 2010. http://dx.doi.org/10.4260/BJFT2010130400040

OZDEMIR, M.; FLOROS, J. D. Active food packaging technologies. Critical Reviews in Food Science and Nutrition, Philadelphia, v. 44, n. 3, p. 185-193, 2004. http://dx.doi. org/10.1080/10408690490441578

ROBERTSON, G. L. Food Packaging, Principles and Practice. 2th ed. London: CRC Press, 2005. 568 p.

ROLLER, S.; SEEDHAR, P. Carvacrol and cinnamic acid inhibit microbial growth in fresh-cut melon and kiwifruit at $4^{\circ} \mathrm{C}$ and $8^{\circ} \mathrm{C}$. Letters in Applied Microbiology, Oxford, v. 35, n. 5, p. 390-394, 2002. http://dx.doi.org/10.1046/j.1472-765X.2002.01209.x

SANLA-EAD, N.; JANGCHUD, A.; CHONHENCHOB, V.; SUPPAKUL P. Antimicrobial activity of cinnamaldehyde and eugenol and their activity after incorporation into cellulosebased packaging film. Packaging Technology and Science,
Singapore, v. 25, n. 1, p. 7-17, 2012. http://dx.doi.org/10.1002/ pts.952

SILVEIRA, M. F. A. Filme Antimicrobiano Incorporado com Ácido Sórbico na Conservação de Massa de Pastel. 2005. 64 f. Tese (Doutorado em Ciência e Tecnologia de Alimentos)Universidade Federal de Viçosa, Viçosa, 2005.

SIVAKUMAR, D.; WIJERATNAM, R. S. W.; WIJESUNDERA, R. L. C.; ABEYESEKERE, M. Control of postharvest diseases of rambutan using cinnamaldehyde. Crop Protection, Guildford, v. 21, n. 9, p. 847-852, 2002.

SOARES, N. F. F.; HOTCHKISS, J. H. Bitterness reduction in grapefruit juice through active packaging. Packaging Technology and Science, Singapore, v. 11, n. 1, p. 9-18, 1998. http://dx.doi.org/10.1002/(SICI)1099-1522(199802)11:1<9::AIDPTS413>3.0.CO;2-D

SUPPAKUL, P.; MILTZ, J.; SONNEVELD, K.; BIGGER, S. W. LOSS of additives from antimicrobial films during storage. Journal of Food Engineering, Oxford, v. 105, n. 2, p. 270-276, 2011. http:// dx.doi.org/10.1016/j.jfoodeng.2011.02.031

SUPPAKUL, P.; MILTZ, J.; SONNEVELD, K.; BIGGER, S. W. Antimicrobial properties of basil and its possible application in food packaging. Journal of Agricultural and Food Chemistry, Washington, v. 51, n. 11, p. 3197-3207, 2003. PMid:12744643. http://dx.doi.org/10.1021/jf021038t

TOLEDO, M. M. Crescimento de Lactococcus lactis subsp. lactis NCK 400 e Produção de Nisina em Meio à Base de Extratos Vegetais. 2000. 66 f. Dissertação (Mestrado em Ciência e Tecnologia de Alimentos)-Universidade Federal de Viçosa, Viçosa, 2000.

YAMASHITA, F.; NAKAGAWA, A.; VEIGA, G. F.; MALI, S.; GROSSMANN, I. V. E. Embalagem ativa para frutos de acerola. Brazilian Journal of Food Technology, Campinas, v. 9, n. 2, p. 95-100, 2006.

YAMAZAKI, K.; YAMAMOTO, T.; KAWAI, Y.; INOUE, N. Enhancement of antilisterial activity of essential oil constituents by nisin and diglycerol fatty acid ester. Food Microbiology, London, v. 21, n. 3, p. 283-289, 2004. http://dx.doi.org/10.1016/j. $\mathrm{fm} .2003 .08 .009$ 